\title{
Performance of ZnO Nanoparticles for Fire Retardant and UV Protection of Pine Wood
}

\begin{abstract}
Higor Rogerio Favarim* and Lucas Oliveira Leite
The aim of this paper was to investigate the influence of zinc oxide $(\mathrm{ZnO})$ nanoparticles on the resistance of pine wood to fire and ultraviolet (UV) radiation. The $\mathrm{ZnO}$ nanoparticles were prepared from aqueous zinc nitrate via a proteic sol-gel method. Dried samples were impregnated using immersion in an aqueous solution of $\mathrm{ZnO}$ nanoparticles in the amount of $1 \mathrm{wt} . \%$ wood. Samples were exposed to an open flame to test the fire retardance, and a high-pressure UV lamp was used to test the UV resistance. The results showed an improvement in the fire retardance and $\mathrm{UV}$ radiation resistance after the impregnation of $\mathrm{ZnO}$ nanoparticles.
\end{abstract}

Keywords: ZnO nanoparticles; Pine wood; UV resistance; Fire resistance; Proteic sol-gel method

Contact information: São Paulo State University (UNESP), Campus Itapeva, Rua Geraldo Alckmin, 519, 18409-010 Itapeva, SP, Brazil; *Corresponding author: higor.favarim@unesp.br

\section{INTRODUCTION}

Wood is widely used because of its excellent versatility. It has great characteristics, such as a low cost, high mechanical resistance, and good thermal and acoustic insulation properties. As wood is a material that can be naturally degraded by weathering, attacks by xylophagous agents, and higher temperatures, protection must be used to maintain the original properties of the wood (Scheffer 1973; Zabel and Morrel 1992).

To prevent variation in the wood properties, several protective agents have been applied to wood, the most common of which is the application of thin coatings of oil, paints, and varnishes. Currently, nanostructured materials have a wide range of applications, especially as wood preservatives in lignocellulosic systems (Farahani and Banikarim 2013; Palanti and Feci 2013; Taghiyari et al. 2014; Tuong and Chu 2015; Pánek and Reinprecht 2016) and for improving physico-mechanical and thermal properties (Lee et al. 2010; Cristea et al. 2011; Zhao et al. 2011).

In particular, zinc oxide $(\mathrm{ZnO})$ nanoparticles have attracted attention because of their characteristics, such as their biocompatibility, good chemical stability, and great absorption performance. Numerous studies have shown the viability of using $\mathrm{ZnO}$ in ultraviolet (UV) stabilizer coatings and as a wood preservative (Bongiovanni et al. 2002; Cristea et al. 2010; Salla et al. 2012; Samanta et al. 2017).

The main objective of this paper was to evaluate the effect on the flame retardance and UV resistant capabilities by adding $1 \% \mathrm{ZnO}$ nanoparticles to pine wood samples synthesized through a simple process. 


\section{EXPERIMENTAL}

\section{Materials}

Zinc acetate hexahydrate (98\% pure) and gelatin (Synth, São Paulo, Brazil) were used without further purification. Wood samples with the dimensions $50 \mathrm{~mm} \times 30 \mathrm{~mm} \times$ $20 \mathrm{~mm}$ (length $\times$ width $\times$ thickness) were prepared from pine wood (Pinus elliottii) via cutting parallel to the fibres (radial direction).

\section{Methods}

Nanoparticle synthesis

Zinc oxide nanoparticles were synthesized via a proteic sol-gel process (de Andrade Gomes et al. 2013). Equal amounts of zinc acetate hexahydrate and gelatin were dissolved in deionized water through continuous stirring and then heated to form the gel. The first thermal treatment at $200{ }^{\circ} \mathrm{C}$ for 15 min partially removed organic elements from the raw powder. Another thermal treatment at $550{ }^{\circ} \mathrm{C}$ for $3 \mathrm{~h}$ was performed to remove the residual organic elements and obtain the desired crystalline phase.

\section{Treatment of the specimens}

All of the samples were dried in an oven at $103{ }^{\circ} \mathrm{C}$ for 1 day for mass determination and were conditioned in a climate chamber at $20^{\circ} \mathrm{C}$ until an equilibrium moisture content was reached $(12 \%)$. Zinc oxide nanoparticles were dispersed in deionized water by ultrasonic agitation in the amount of $1 \mathrm{wt} . \%$ wood. Dried wood samples were immersed in an aqueous solution of nanoparticles with continuous stirring for 1 day and were then referred to as $\mathrm{ZnO}$-treated. Non-treated wood samples were immersed in deionized water to ensure identical test conditions, and those samples were referred to as natural. After the immersion process, all of the samples were dried in an oven at $103{ }^{\circ} \mathrm{C}$ and maintained in a climate chamber until testing. After the impregnation process, it was found that a thin layer of $\mathrm{ZnO}$ adhered to the wood surface. However, both the color and mass remained unchanged after cleaning.

\section{Characterization}

The crystalline phase of the $\mathrm{ZnO}$ was recorded with an X-ray diffractometer (D8 Advance, Bruker AXS, Billerica, EUA) using a $\mathrm{Cu} \mathrm{K} \alpha$ source (1.54 $\AA$, $1.6 \mathrm{~kW}$ ) with a scanning speed of $0.2^{\circ} / \mathrm{s}$ over the range of $20^{\circ}$ to $85^{\circ}$. The crystallite size was estimated with the Scherrer equation, taking into consideration the first nine peaks of the diffraction spectrum.

The flame retardance tests were qualitatively done using a piloted lateral ignition and flame spread test apparatus. Pine wood samples were inclined at $15^{\circ}$ and positioned 12 $\mathrm{cm}$ away from the tip of a butane torch, and the samples were exposed directly to an open flame. The times required to burn through the samples were recorded.

The photostability of the wood surfaces exposed to UV radiation were tested using a UV high-pressure lamp (Ultra Vitalux, Osram, Munich, Germany) that was $30 \mathrm{~cm}$ away from the samples for $80 \mathrm{~h}$ of exposure. The radiated power was $13.6 \mathrm{~W}$ in the wavelength range of $315 \mathrm{~nm}$ to $400 \mathrm{~nm}$ (UVA) and was $3.0 \mathrm{~W}$ in the wavelength range of $208 \mathrm{~nm}$ to $315 \mathrm{~nm}$ (UVB). The system, UV lamp, sample holder, and samples were mounted under an oven chamber and temperatures were kept under $70^{\circ} \mathrm{C}$ throughout the experiment. 


\section{RESULTS AND DISCUSSION}

\section{Nanoparticle Characterization}

The proteic sol-gel technique proved to be effective for the nanostructured $\mathrm{ZnO}$ and made use of low-cost materials and calcined temperatures well below those typically used in traditional methods. The X-ray diffraction (XRD) pattern of the as-prepared powder is shown in Fig. 1. The presence of sharp peaks demonstrated that the synthesized $\mathrm{ZnO}$ nanoparticles were single phase with good crystallinity. Comparison with the data from the Joint Committee on Powder Diffraction Standard (JCPDS) revealed a compact hexagonal wurtzite structure that was in agreement with JCPDS Card No. 36-1451. The crystallite size, as estimated from the X-ray line broadening using the Scherrer equation, was $22 \mathrm{~nm}$.

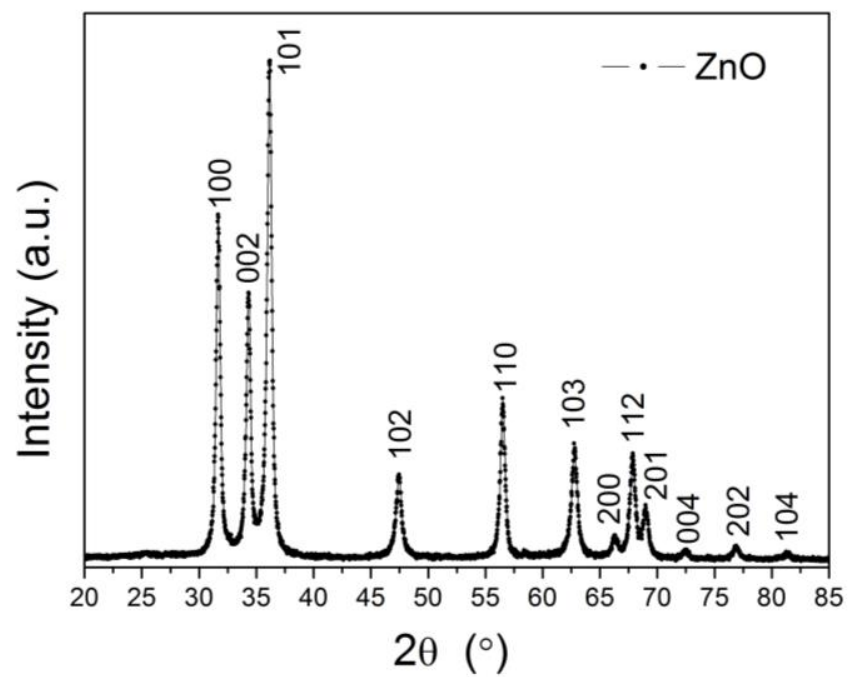

Fig. 1. XRD pattern of the synthesized $\mathrm{ZnO}$ nanoparticles

\section{Flame Test}

Figure 2 displays the cross-cut profile of the specimens subjected to the flame tests. Sample a was composed only of earlywood, sample b presented three latewood rings parallel to the larger face, and samples $\mathrm{c}$ and $\mathrm{d}$ presented two latewood rings parallel to the length. The flame tests were conducted by exposing the larger face to a flame.

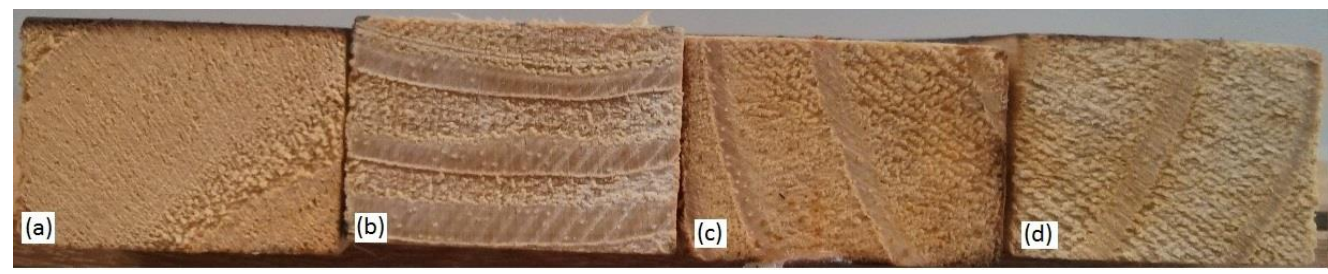

Fig. 2. Cross-cut profile of the samples subjected to the flame tests: (a) sample a, (b) sample b, (c) sample c, and (d) sample d

The results of the flammability tests are shown in Fig. 3. A relevant improvement in the ignition time was observed for samples $\mathrm{b}$ and $\mathrm{c}$, and their combustion times were extended by approximately $60 \%$ and $110 \%$, respectively. In contrast, samples a and d were improved by only about $15 \%$. Analysis of the samples after testing revealed that the 
latewood (higher density) underwent few changes to its characteristics and some rings only became slightly dirty with soot. The less dense wood (earlywood) exhibited high deformation because of a combustion reaction. These results suggested that the $\mathrm{ZnO}$ nanoparticles act as a thermo-protective barrier that prevent the spread of flames, which is in line with other findings given in the literature (Samanta et al. 2017).

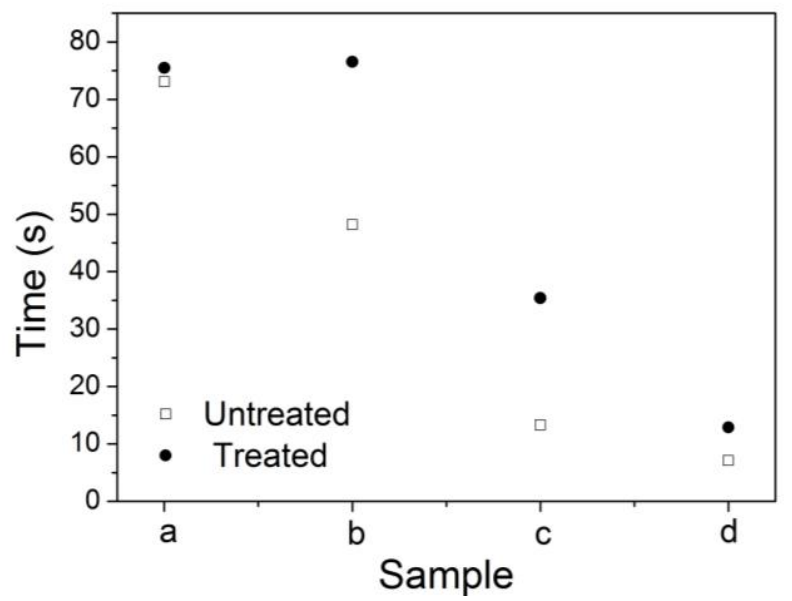

Fig. 3. Change in the ignition time for the samples that underwent flame testing

Despite the improvements observed in all of the samples, the facts that the wood has a higher anisotropy and the same type of structure (visual comparison) did not account for the effectiveness that can be observed in samples $c$ and $d$. However, because it is a simple and low-cost procedure, the small improvements indicate the advantage of this treatment.

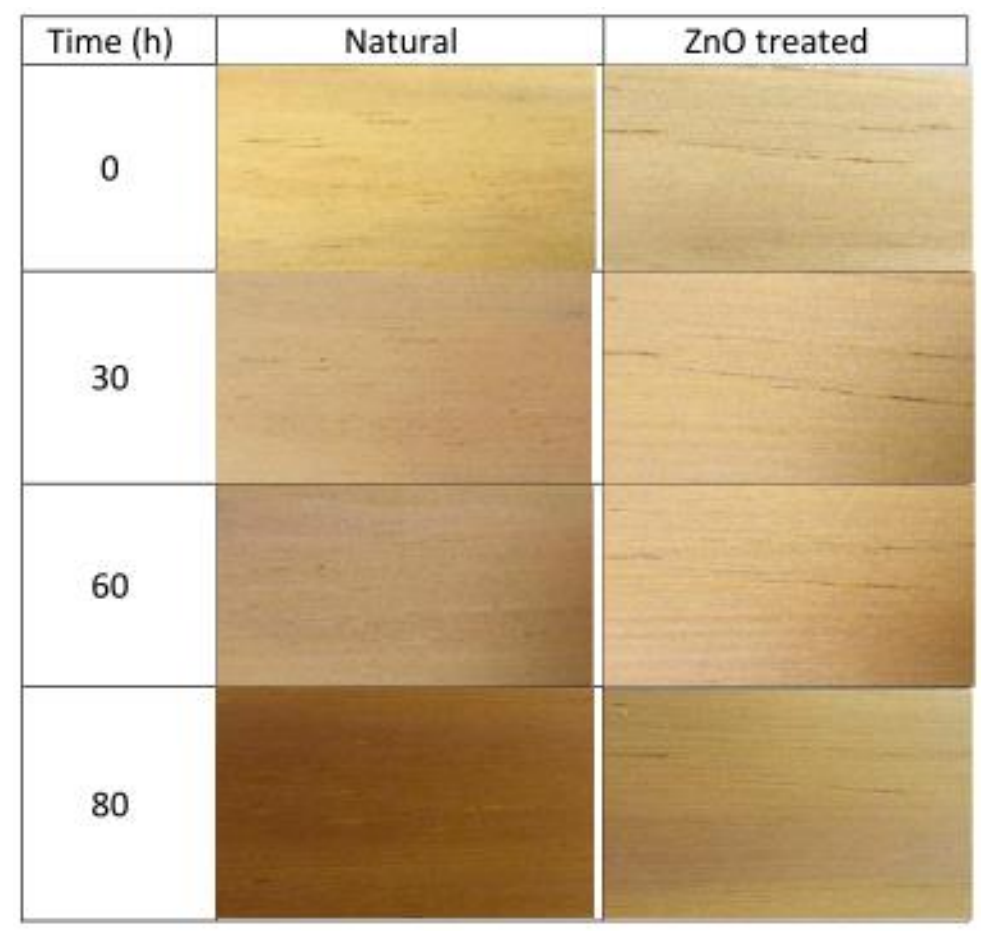

Fig. 4. Changes in the natural and $\mathrm{ZnO}$-treated samples during the UV irradiation testing 


\section{Photostability}

The effect of UV radiation exposure on the surfaces of a series of samples are shown in Fig. 4. The photographs show the responses to UV radiation after $0 \mathrm{~h}, 30 \mathrm{~h}, 60 \mathrm{~h}$, and $80 \mathrm{~h}$ of exposure.

All of the samples showed a similar behavior over time and the surfaces became browner because of degradation caused by the UV radiation. However, the sample impregnated with the $\mathrm{ZnO}$ nanoparticles exhibited a small improvement in the UV resistance. This effect was likely caused by the fact that the $\mathrm{ZnO}$ nanoparticle absorption peak occurs in the UV region, which reduced the direct impact of UV radiation on the wood. The reduction in UV exposure may have occurred via UV scattering and UV absorption by the $\mathrm{ZnO}$ nanoparticles, as the absorbed energy spreads more slowly on treated surfaces than on untreated surfaces. These combined phenomena slowed the aging process of the wood caused by UV exposure. Despite the improvement in retarding wood aging, the absorbed UV radiation in this test had enough energy to decompose and degrade the organic compounds and break the chemical bonds of wood polymers such as lignin.

\section{CONCLUSIONS}

1. The $\mathrm{ZnO}$ nanoparticles synthesized via a proteic sol-gel method were successfully impregnated into pine samples without a complex procedure.

2. The fire protective qualities were verified for all of the impregnated samples, which showed the effectiveness of the $\mathrm{ZnO}$ nanoparticles as a thermal-protective barrier for wood samples. However, due to the high anisotropy of the wood, the nanoparticles may not present the same penetration into the wood, justifying the observed differences in the fire protection tests.

3. The harmful effects of UV radiation exposure were reduced by treatment with $\mathrm{ZnO}$ nanoparticles, which slowed down the browning process of the wood surfaces.

4. Because of the low cost of implementation and low impregnation percentage, $\mathrm{ZnO}$ nanoparticles have great potential for application as protective agents in lingocellulosic systems.

\section{ACKNOWLEDGMENTS}

The authors wish to thank Dr. Maria Inês Basso from CCMC - USP for her assistance with the DRX measurements.

\section{REFERENCES CITED}

Bongiovanni, R., Montefusco, F., Priola, A., Macchioni, N., Lazzeri, S., Sozzi, L., and Ameduri, B. (2002). "High performance UV-cured coatings for wood protection," Prog. Org. Coat. 45(4), 359-363. DOI: 10.1016/S0300-9440(02)00119-4 
Cristea, M. V., Riedl, B., and Blanchet, P. (2010). "Enhancing the performance of exterior waterborne coatings for wood by inorganic nanosized UV absorbers," Prog. Org. Coat. 69(4), 432-431. DOI: 10.1016/j.porgcoat.2010.08.006

Cristea, M. V., Riedl, B., and Blanchet, P. (2011). "Effect of addition of nanosized UV absorbers on the physico-mechanical and thermal properties of an exterior waterborne stain for wood," Prog. Org. Coat. 72(4), 755-762. DOI:

10.1016/j.porgcoat.2011.08.007

de Andrade Gomes, M., Valerio, M. E. G., Rey, J. F. Q., and Macedo, Z. S. (2013). "Comparative study of structural and optical properties of $\mathrm{ZnO}$ nanostructures prepared by three different aqueous solution methods," Mater. Chem. Phys. 142(1), 325-332. DOI: 10.1016/j.matchemphys.2013.07.024

Farahani, M. R., and Banikarim, F. (2013). "Effect of nano-zinc oxide on decay resistance of wood-plastic composites," BioResources 8(4), 5715-5720. DOI: 10.15376/biores.8.4.5715-5720

Lee, Y. H., Kuboki, T., Park, C. B, Sain, M., and Kontopoulou, M. (2010). "The effects of clay dispersion on the mechanical, physical, and flame-retarding properties of wood fiber/polyethylene/clay nanocomposites," J. Appl. Polym. Sci. 118(1), 452-461. DOI: 10.1002/app.32045

Palanti, S., and Feci, E. (2013). "A wood preservative based on commercial silica nanodispersions and boric acid against fungal decay through laboratory and field tests," Open Journal of Forestry 3(2), 57-61. DOI: 10.4236/ojf.2013.32009

Pánek, M., and Reinprecht, L. (2016). "Effect of the number of UV-protective coats on the color stability and surface defects of painted black locusts and Norway spruce woods subjected to natural weathering," BioResources 11(2), 4663-4676. DOI: 10.15376/biores.11.2.4663-4676

Salla, J., Pandey, K. K., and Srinivas, K. (2012). "Improvement of UV resistance of wood surfaces by using ZnO nanoparticles," Polym. Degrad. Stabil. 97(4), 592-596. DOI: 10.1016/j.polymdegradstab.2012.01.013

Samanta, A. K., Bhattacharyya, R., Jose, S., Basu, G., and Chowdhury, R. (2017). "Fire retardant finish of jute fabric with nano zinc oxide," Cellulose 24(2), 1143-1157. DOI: $10.1007 / \mathrm{s} 10570-016-1171-\mathrm{z}$

Scheffer, T. C. (1973). "Microbiological degradation and the causal organisms," in Wood Deterioration and Its Prevention by Preservative Treatments: Volume 1 Degradation and Protection of Wood, D. D. Nicholas (ed.), Syracuse University Press, Syracuse, NY, pp. 31-106.

Taghiyari, H. R., Bari, E., Schmidt, O., Ghanbary, M. A. T., Karimi, A., and Tahir, P. M. (2014). "Effects of nanowollastonite on biological resistance of particleboard made from wood chips and chicken feather against Antrodia vaillantii," Int. Biodeter. Biodegr. 90, 93-98. DOI: 10.1016/j.ibiod.2014.02.012

Tuong, V. M., and Chu, T. V. (2015). "Improvement of color stability of Acacia hybrid wood by $\mathrm{TiO}_{2}$ nano sol impregnation," BioResources 10(3), 5417-5425. DOI: 10.15376/biores.10.3.5417-5425

Zabel, R. A., and Morrel, J. J. (1992). “Chemical protection of wood," in Wood Microbiology: Decay and its Prevention, Academic Press, San Diego, CA, pp. 412422. 
Zhao, G., Guo, Q., Yi, J., and Cai, X. (2011). "Synergistic effect of zinc oxide on the flame retardant and thermal properties of acrylonitrile-butadienestyrene/poly(ethylene terephthalate)/ammonium polyphosphate systems," J. Appl. Polym. Sci. 122(4), 2338-2344. DOI: 10.1002/app.34039

Article submitted: March 22, 2018; Peer review completed: May 5, 2018; Revised version received: July 24, 2018; Accepted: July 25, 2018; Published: July 31, 2018. DOI: 10.15376/biores.13.3.6963-6969 